\title{
Relationship between malnutrition and the presence of symptoms of anxiety and depression in hospitalized cancer patients
}

\author{
Francisco José Sánchez-Torralvo ${ }^{1,2,3}$ • Victoria Contreras-Bolívar ${ }^{4}$ María Ruiz-Vico ${ }^{5}$. José Abuín-Fernández ${ }^{1,2,3}$. \\ Inmaculada González-Almendros ${ }^{6} \cdot$ Manuel Barrios $^{7} \cdot$ Gabriel Olveira $^{1,2,3}$
}

Received: 16 April 2021 / Accepted: 30 August 2021 / Published online: 21 September 2021

(c) The Author(s) 2021, corrected publication 2022

\begin{abstract}
Background Anxiety and depression are a common issue in patients with cancer, yet understudied among hospitalized patients. The aim of this study was to estimate the prevalence of anxiety and depression symptomatology in cancer inpatients and its relationship with malnutrition.

Methods Cross-sectional study in hospitalized cancer patients. A nutritional assessment was done using the Global Leadership Initiative on Malnutrition (GLIM) criteria to diagnose malnutrition. Data regarding anxiety and depression symptomatology was obtained with the Hospital Anxiety and Depression Scale (HADS).

Results A total of 282 inpatients were assessed. GLIM criteria found $20 \%$ (66) of well-nourished and $80 \%$ (216) with malnutrition. HADS presented an average score of $8.3 \pm 4.4$ with respect to anxiety and an average score of $7.7 \pm 4.6$ with respect to depression. Up to $54 \%$ of the patients showed a possible presence of anxiety, and $45.3 \%$ of them showed a possible presence of depression. In malnourished patients, HADS score was non-significantly higher with respect to anxiety $(8.5 \pm 4.3$ in malnourished vs $7.1 \pm 4.6$ in well-nourished; $p=0.06)$ and was significantly higher with respect to depression $(8.2 \pm 4.6$ in malnourished vs $5.3 \pm 4.0$ in well-nourished; $p<0.001$ ). After controlling for potential confounders, malnourished patients were 1.98 times more likely to present anxious symptomatology $(95 \%$ CI $1.01-3.98 ; p=0.049)$ and 6.29 times more likely to present depressive symptomatology (95\% CI 1.73-20.47; $p=0.005)$.

Conclusions The presence of anxiety and depression symptomatology in oncological inpatients is high. There is an association between malnutrition and presenting anxious and depressive symptomatology in hospitalized cancer patients.
\end{abstract}

Keywords Cancer · Oncology $\cdot$ Anxiety $\cdot$ Depression $\cdot$ HADS $\cdot$ Malnutrition $\cdot$ GLIM criteria

\section{Introduction}

Francisco José Sánchez-Torralvo

fransancheztorralvo@gmail.com

1 Unidad de Gestión Clínica de Endocrinología y Nutrición, Hospital Regional Universitario de Málaga, Málaga, Spain

2 Instituto de Investigación Biomédica de Málaga (IBIMA), Málaga, Spain

3 Universidad de Málaga, Málaga, Spain

4 Unidad de Gestión Clínica de Endocrinología Y Nutrición, Hospital Universitario San Cecilio, Granada, Spain

5 Unidad de Gestión Clínica de Oncología Médica, Hospital Regional Universitario de Málaga, Málaga, Spain

6 Unidad de Gestión Clínica de Radiodiagnóstico, Hospital Regional Universitario de Málaga, Málaga, Spain

7 Unidad de Gestión Clínica de Hematología y Hemoterapia, Hospital Regional Universitario de Málaga, Málaga, Spain
Cancer disease and nutritional status are closely related, as symptoms caused by the disease, the associated secondary complications, and the antineoplastic therapies increase the risk of an impaired nutritional status [1, 2]. Malnutrition, defined as "a state resulting from lack of intake or uptake of nutrition that leads to altered body composition and body cell mass leading to diminished physical and mental function and impaired clinical outcome from disease" [3], is a common issue among patients with cancer, being present in up to $80 \%$ of them and increasing morbidity and mortality [4]. The prevalence of malnutrition increases in advanced-stage cancer patients who require hospital admission [5].

In cancer patients, the presence of psychological problems such as depression and anxiety can make it difficult to manage and control the disease [6]. Previous studies have 
reported that the prevalence of depression among cancer patients is two to three times higher than in the general population [7]. Depression and anxiety occur up to $20 \%$ and $10 \%$ of patients with cancer, respectively [8], although the figures vary depending on factors such as the stage of the disease or the phase of treatment $[8,9]$. Thus, some authors estimate a higher prevalence, especially in patients with advanced cancer or palliative therapy $[10,11]$.

Depression is associated with poor adherence to cancer treatment and poor cancer survival [12]. Depression and anxiety disorder are associated with an increased risk of mortality and their co-occurrence further increased the risk [13]. Cancer patients with anxiety and depression were at greater risk for emergency department visits and hospitalizations, experienced longer hospital stays, and accrued higher healthcare costs [14].

The relationship between malnutrition and psychological distress has been described in cancer patients. Patients experiencing weight loss and other symptoms of malnutrition often report higher levels of psychological distress, which manifest as more severe fatigue, insomnia, anxiety, and depression, further contributing to disease progression [15]. The symptoms of malnutrition and psychological distress overlap, but few studies have focused on the relationship between them, being depression and anxiety the problems most frequently endorsed by patients as contributing to its appearance [16]. With regard to depression specifically, there are studies that indicate its relationship with less food consumption, weight loss, and malnutrition [16, 17].

As far as we know, published data on the prevalence of symptoms of anxiety and depression at its relationship with malnutrition in hospitalized cancer patients are scarce [18]. These patients also tend to have more advanced stages, which could condition this possible association.

Our hypothesis is that the prevalence of anxiety and depression symptoms is high in hospitalized cancer patients and is related to the high rate of malnutrition in these patients [5].

The aim of the study was to assess the relationship between malnutrition and the level of anxiety and depression in hospitalized patients with cancer.

\section{Methods}

This was an observational, prospective study of clinical practice performed at Hospital Regional Universitario de Málaga. A total of 351 patients were assessed for eligibility after admission to the oncology ward. Inclusion criteria were patients with solid or hematological neoplasm, length of stay above $48 \mathrm{~h}$, and able to sign the informed consent. Exclusion criteria were patients with length of stay below $48 \mathrm{~h}$, readmission before $1 \mathrm{month}$, and a situation of actively dying. After screening of inclusion/exclusion criteria, 282 patients were included and 69 were excluded (Fig. 1).

\section{Assessment of malnutrition}

We performed a nutritional assessment according to GLIM criteria within the first $24 \mathrm{~h}$ after admission. To diagnose malnutrition, at least one phenotypic criterion and one etiologic criterion should be present [19].

\section{Phenotypic criteria}

We assessed unintentional weight loss ( $>5 \%$ in 6 months), low BMI (for age $<70$ years normal values were considered as $\mathrm{BMI} \geq 20 \mathrm{~kg} / \mathrm{m}^{2}$, and for age $\geq 70$ normal values were established as BMI $\geq 22 \mathrm{~kg} / \mathrm{m}^{2}$ ), and/or reduction of muscle mass basing hand grip strength (HGS). Weight was assessed with a weighing scale adjusted to $0.1 \mathrm{~kg}$ (SECA 665, Germany) and height was obtained by a stadiometer (Holtain Limited, Crymuch, UK). With these two values, body mass index (BMI) was calculated.

\section{Study Flow Diagram}

$$
\text { Assessed for eligibility }(n=351)
$$

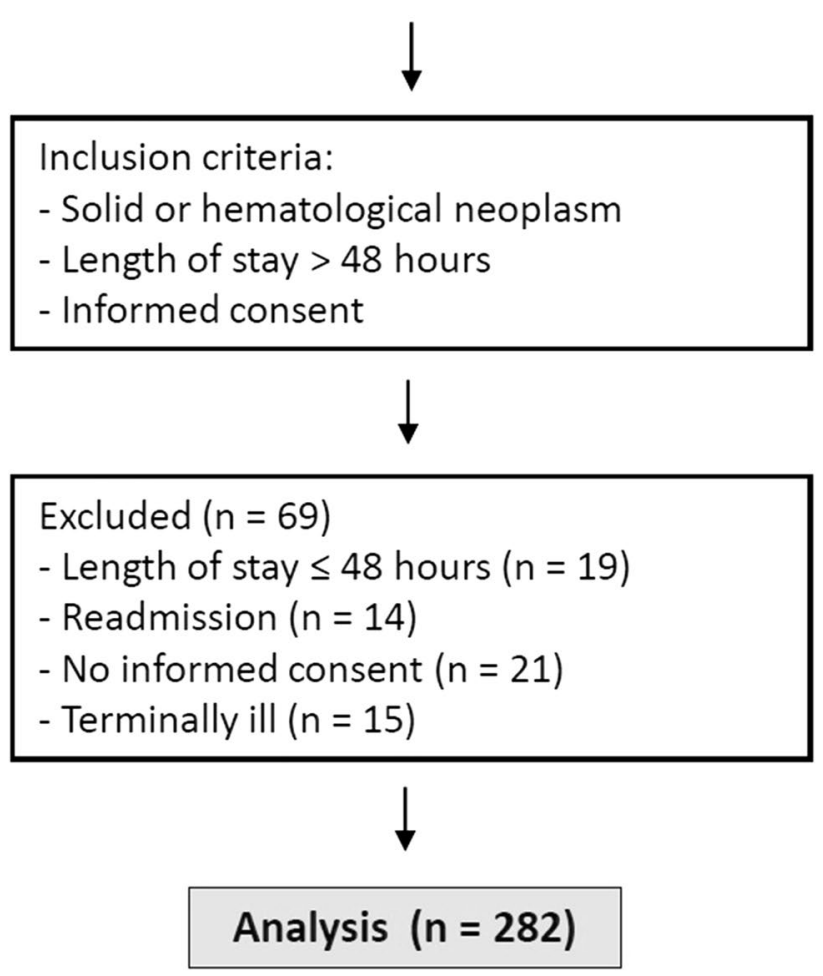

Fig. 1 Study flow diagram 
Handgrip strength was used to estimate muscle mass [5] and was measured in the dominant hand with a Jamar dynamometer (Asimow Engineering Co., Los Angeles, CA). The patients performed the test while sitting with shoulder adducted and forearm neutrally rotated, elbow flexed to $90^{\circ}$, and forearm and wrist in neutral position. Patients were told to perform three consecutive contractions $1 \mathrm{~min}$ apart from each other, and mean value was calculated. Results were expressed in absolute figures and compared with the reference population [20]. Values under the fifth percentile were considered as low strength.

\section{Etiologic criteria}

Etiologic criteria were assessed by reduced food intake (estimated as per quartiles) or assimilation (as per clinical record), and/or inflammatory response of the disease (patients were considered as presenting chronic diseaserelated inflammation using Glasgow prognostic score) [19, 21].

\section{The questionnaire}

The presence of symptoms of anxiety and depression was measured with Hospital Anxiety and Depression Scale (HADS) questionnaire. The HADS is a brief patient selfreport measure of anxiety and depression requiring patients to report their symptoms during the previous week [22]. The HADS has demonstrated reliability and validity in cancer patient populations [23] and has been found to be an effective screening tool for cancer patients currently undergoing treatment [24].

The HADS consists of 14 items and two subscales, one measuring anxiety (HADS Anxiety subscale), with seven items, and another measuring depression (HADS Depression subscale), with seven items, which score separately.

HADS Anxiety subscale focus mainly on symptoms of generalized anxiety disorder and HADS Depression subscale is focused on anhedonia, the main symptom of depression. Each item is scored on a response-scale with four alternatives ranging between 0 and 3 . The possible scores range from 0 to 21 for each of the two subscales, taking 2-5 min to complete [22]. Subscale scores from 0 to 7 are classified as normal. Subscale scores ranging from 8 to 11 are typically used for identifying the possible presence of anxiety and depression ("doubtful cases") and subscale scores over 11 indicates the probable presence ("caseness") of a mood disorder [25].

\section{Data analysis}

Quantitative variables were expressed as the mean \pm standard deviation. Quantitative variables distribution was assessed using Kolmogorov-Smirnov test. Differences between quantitative variables were analyzed using Student's $t$ test and, for variables not following a normal distribution, using nonparametric tests (Mann-Whitney or Kruskal-Wallis). We designed multivariate logistic regression models in which the dependent variable was the cut-off points of the HADS subscales according to malnutrition determined by GLIM criteria, controlling also for sex, age, and tumor stage. For calculations, significance was set at $p<0.05$ for two tails. The data analysis was performed with the SPSS 22.0 program (SPSS Inc., Chicago, IL, 2013).

\section{Results}

A total of 282 patients admitted to inpatient oncology unit were evaluated. Mean age was $60.4 \pm 12.6$ years, $55.7 \%$ were male. Their general features are displayed in Table 1 . Most patients (92.9\%) had an advanced-stage tumor (17.7\%

Table 1 General features. Prevalence of anxiety and depression symptomatology

\begin{tabular}{|c|c|c|}
\hline & & $n=282$ \\
\hline Age (years) & Mean \pm SD & $60.4 \pm 12.6$ \\
\hline Sex & $n(\%)$ & \\
\hline Men & & $157(55.7)$ \\
\hline Women & & $125(44.3)$ \\
\hline Tumor stage & $n(\%)$ & \\
\hline $\mathrm{I}$ & & $7(2.5)$ \\
\hline II & & $13(4.6)$ \\
\hline III & & $50(17.7)$ \\
\hline IV & & $212(75.2)$ \\
\hline $\mathrm{BMI}\left(\mathrm{kg} / \mathrm{m}^{2}\right)$ & Mean \pm SD & \\
\hline Men & & $24.7 \pm 4.9$ \\
\hline Women & & $24.5 \pm 5.1$ \\
\hline Hand-grip strength $(\mathrm{kg})$ & Mean \pm SD & \\
\hline Men & & $26.21 \pm 8.58$ \\
\hline Women & & $16.51 \pm 6.70$ \\
\hline Malnutrition according to GLIM criteria & $n(\%)$ & $216(80 \%)$ \\
\hline HADSA score & Mean \pm SD & $8.30 \pm 4.40$ \\
\hline HADSD score & Mean \pm SD & $7.68 \pm 4.61$ \\
\hline Possible presence of anxiety (HADSA $\geq 8$ ) & $n(\%)$ & $127(54 \%)$ \\
\hline $\begin{array}{l}\text { Possible presence of depression } \\
\quad(\text { HADSD } \geq 8)\end{array}$ & $n(\%)$ & $106(45.3 \%)$ \\
\hline $\begin{array}{l}\text { Probable presence of anxiety } \\
\quad(\text { HADSA } \geq 11)\end{array}$ & $n(\%)$ & $62(26.4 \%)$ \\
\hline $\begin{array}{l}\text { Probable presence of depression } \\
\quad(\text { HADSD } \geq 11)\end{array}$ & $n(\%)$ & $63(26.9 \%)$ \\
\hline
\end{tabular}

$B M I$ body mass index; GLIM Global Leadership Initiative on Malnutrition; HADSA Hospital Anxiety and Depression Scale Anxiety subscale; HADSD Hospital Anxiety and Depression Scale Depression subscale; $S D$ standard deviation 
stage III, $75.2 \%$ stage IV). The most frequent types of neoplasm were lung (25.2\%), colon (13.0\%), breast (13\%), and esophagogastric (11.8\%). At the moment of admission, a nutritional assessment according to GLIM criteria was performed, detecting $80 \%$ (216) of patients with malnutrition (Table 1). Furthermore, only 20.6\% (58) of the patients had a low BMI and 37.9\% (107) had a low HGS, which could be related to a high prevalence of sarcopenic obesity.

HADS presented an average score of $8.3 \pm 4.4$ points with respect to anxiety $(8.0 \pm 4.5$ points in male vs $8.7 \pm 4.3$ points in female) and an average score of $7.7 \pm 4.6$ with respect to depression $(7.5 \pm 4.8$ points in male vs $7.8 \pm 4.3$ points in female). With these data, $54 \%$ of our patients showed a possible presence of anxiety and $45.3 \%$ showed a possible presence of depression.

In malnourished patients according to GLIM criteria, average score was non-significantly higher with respect to anxiety $(8.5 \pm 4.3$ points in malnourished vs $7.1 \pm 4.6$ in well-nourished; $p=0.06$ ) and was significantly higher with respect to depression $(8.2 \pm 4.6$ points in malnourished vs $5.3 \pm 4.0$ points in well-nourished; $p<0.001$ ) (Fig. 2).

Table 2 shows the logistic regression data (crude and adjusted) for the risk of presenting anxious or depression symptomatology in malnourished patients. After controlling for potential confounders, in malnourished patients according to GLIM criteria, the odds ratio of presenting anxious symptomatology was 1.98 times greater than in well-nourished [95\% CI 0.99-3.98; $p=0.05$ ] and the odds ratio of presenting depression symptomatology in these patients was 6.29 times greater than in well-nourished [95\% CI $1.73-20.47 ; p=0.005]$.

\section{Discussion}

The presence of anxiety and depression symptomatology in cancer inpatients is high, and there is an association between this symptomatology and malnutrition in our study.

We used HADS questionnaire to identify anxiety and depressive symptoms. Cancer research has extensively applied subscale thresholds of 11 to indicate the likely presence of anxiety and/or depression, reported as achieving $70-95 \%$ sensitivity and $83 \%$ specificity with respect to clinical interview [26] although some authors suggest that the recommended cut-off scores for the HADS may result in under-reporting of psychiatric morbidity among patients
Fig. 2 Association between malnutrition and HADS Anxiety and Depression subscales

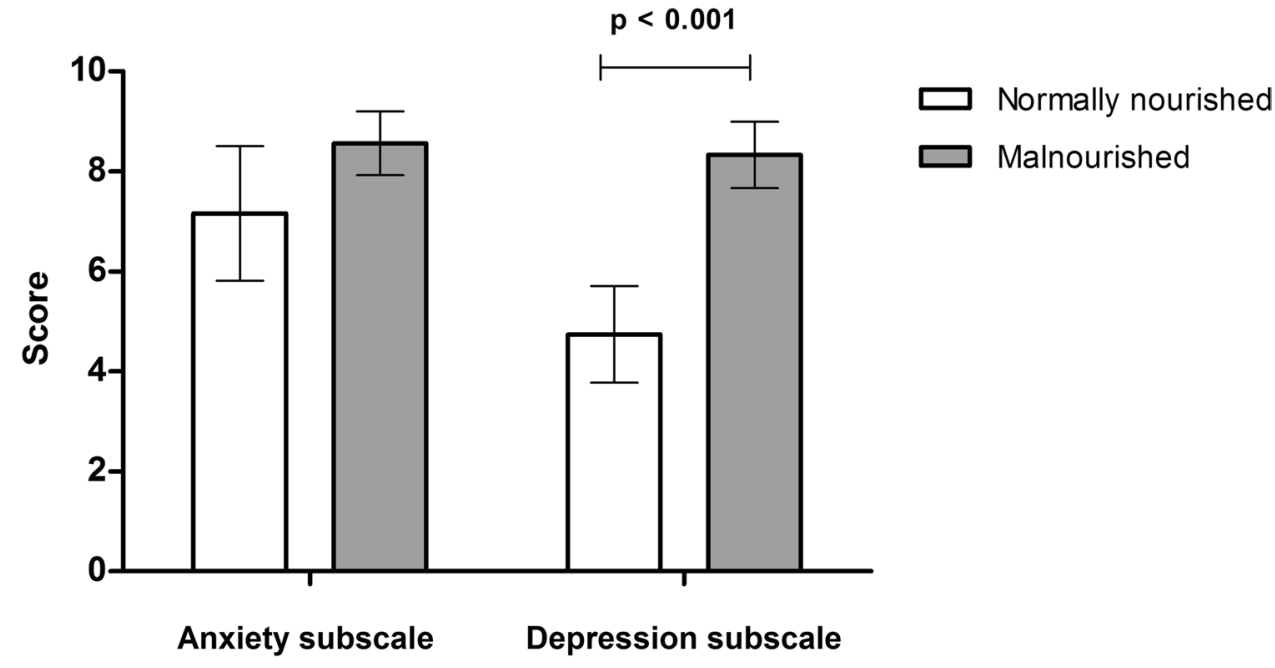

Table 2 Risk of presenting anxious or depression symptomatology in malnourished patients. Adjusted for age, sex, and cancer stage

\begin{tabular}{|c|c|c|c|c|c|c|c|c|}
\hline & \multicolumn{4}{|l|}{ Crude } & \multicolumn{4}{|l|}{ Adjusted } \\
\hline & \multirow[t]{2}{*}{ Odds ratio } & \multicolumn{2}{|c|}{$95 \% \mathrm{CI}$} & \multirow[t]{2}{*}{$P$ value } & \multirow[t]{2}{*}{ Odds ratio } & \multicolumn{2}{|c|}{$95 \% \mathrm{CI}$} & \multirow[t]{2}{*}{$P$ value } \\
\hline & & Lower & Upper & & & Lower & Upper & \\
\hline Possible presence of anxiety (HADSA $\geq 8$ ) & 2.06 & 1.04 & 4.06 & $\mathbf{0 . 0 3 7}$ & 1.98 & 1.01 & 3.98 & 0.049 \\
\hline Probable presence of anxiety (HADSA $\geq 11$ ) & 1.03 & 0.48 & 2.21 & 0.93 & 1.05 & 0.48 & 2.32 & 0.89 \\
\hline Possible presence of depression (HADSD $\geq 8$ ) & 6.73 & 2.71 & 16.73 & $<0.001$ & 6.29 & 2.51 & 15.75 & $<0.001$ \\
\hline Probable presence of depression $(\mathrm{HADSD} \geq 11)$ & 6.08 & 1.81 & 20.48 & 0.004 & 5.95 & 1.73 & 20.47 & 0.005 \\
\hline
\end{tabular}

Bold: statistically significant 
with cancer [27]. An optimal balance between sensitivity and specificity was found using a cut-off score of 8 or above for both HADS Anxiety and HADS Depression [26].

Previous studies in cancer patients found a prevalence of $12-15 \%$ of anxiety symptomatology and a prevalence of 5.7-7\% of depression symptomatology using HADS threshold of $\geq 11$ [28]. In the present study, using a HADS threshold of $\geq 11,26.9 \%$ of patients were identified with a likely presence of depression and $24.4 \%$ of them were identified with a probable presence of anxiety. Using a HADS threshold of $\geq 8$, highlights that close to half of respondents were identified with a likely presence of depression and $54 \%$ of them were identified with a probable presence of anxiety.

Even using a HADS threshold of $\geq 11$, the rate of anxiety and depression symptomatology in our series is higher than in the series previously described.

Most of the patients of our study (92.9\%) had an advanced-stage tumor (17.7\% stage III, $75.2 \%$ stage IV), many of them under palliative therapy. Prevalence of anxiety and depression is high in advanced stages of the disease. Světláková et al. found that the baseline prevalence of anxiety and depression symptomatology in 126 patients treated with palliative systemic therapy for advanced cancer was 35.9 and $56.5 \%$, respectively [11].

Figures also vary by cancer type, with depression affecting an estimated $17.9 \%$ of patients with lung cancer, $16.5 \%$ of those with gynecological cancers, $15.6 \%$ in breast cancer, $13.2 \%$ in genitourinary cancers, and $10.7 \%$ in gastrointestinal cancers [7]. The highest levels of anxiety are reported in gynecological, lung, head, and neck and breast cancers [7]. The most frequent types of neoplasm in our series were lung $(25.2 \%)$ and breast (13\%), which could explain higher rates of anxious and depressive symptoms.

A review and meta-analysis showed the prevalence of major depression (15\%), minor depression (20\%), and anxiety $(10 \%)$ in patients treated for cancer [8].

Linden et al. performed a study with 10,153 cancer outpatients using the Psychosocial Screen for Cancer questionnaire, a cancer-specific screening instrument for anxiety and depression that was validated using the HADS questionnaire [29]. Across cancer types, $19.0 \%$ of patients showed clinical levels of anxiety and another $22.6 \%$ had subclinical symptoms. Further, $12.9 \%$ of patients reported clinical symptoms of depression and an additional 16.5\% described subclinical symptoms [7].

Brintzenhofe-Szoc et al. performed a study in a 8235 adult outpatients using the Brief Symptom Inventory questionnaire (BSI-18), a widely used screening measure in cancer patients that contains three subscales: somatization, anxiety, and depression [30]. Mixed anxiety/depression symptoms were seen in $12.4 \%$ of patients; depression symptoms in $18.3 \%$, and anxiety symptoms in $24.0 \%$ [31]. A former study conducted in Spain [10], which included outpatients who had undergone cancer surgery in the previous month and who initiated adjuvant chemotherapy, showed a prevalence of malnutrition of $36.4 \%$, depression symptoms in $35.5 \%$, and anxiety symptoms in $35.2 \%$ of the patients using also the BSI- 18 .

We found an association between presenting anxious and depression symptomatology and malnutrition. Previous studies also point towards this association [18, 32-36]. Chabowski et al. found that malnutrition is associated with a significant worsening in terms of depression, anxiety, and pain. [18]. Gosak et al. found a significant correlation between malnutrition and HADS scores, with more distressed patients found in the malnourished/cachectic subgroups [33]. Santos et al. found the presence of depression in $52.9 \%$ elderly malnourished patients undergoing treatment for cancer [37]. The utility of a short depression screening in predicting malnutrition has been demonstrated [35].

The link between malnutrition and major depression is both complicated and correlative. It remains unclear whether depression in cancer patients is the cause or consequence of impaired nutritional status [38]. Van Liew et al. demonstrated that there is a direct reciprocal association between depressive symptoms and weight loss: changes in either variable were associated with concurrent changes in the other variable [36]. Therefore, depression might lead to a lack of appetite, loss of interest in self-care, apathy, and physical weakness. These conditions appear to be linked in a cycle whereby major depression might cause anorexia and result in malnutrition, whereas malnutrition related with cancer directly impair appetite [34]. Biological mechanisms linking distress and malnutrition have been identified, suggesting a link between cancer-related anorexia and depression caused by an impairment of serotonin [16].

The presence of malnutrition and poor recognition of depression and anxiety is strongly associated with reduced quality of life and survival in cancer patients $[10,12,13]$. However, given that some risk factors for nutritional decline in cancer patients are non-modifiable (e.g., stage, site, treatment), it is noteworthy that psychological symptoms are treatable, which may lead to an improvement in nutritional status [39]. However, 73\% of these depressed cancer patients do not receive effective psychiatric treatment, and only $5 \%$ see a mental health professional [6]. These observations underline the importance of the assessment and treatment of both psychological symptoms and nutritional assessment.

Our study has several strengths; it includes a sufficient sample size to achieve adequate statistical power. Furthermore, it includes techniques that are already routinely taken, making it easily applicable to a clinical setting.

All the same, there are potential limitations in our study. It was a single-center cross-sectional study; thus, results should be interpreted with caution. It could only provide clues for a causality relationship between these two factors, 
without ruling out reverse causation. Besides, our study lacks a screening for anxiety, depression or eating disorders prior to cancer diagnosis, which could have yielded more accurate figures for the incidence of these conditions.

The high rates of anxiety and depression symptomatology found in our study, and the strong relationship found between malnutrition and psychological distress are a robust argument for implementation of systematic screening for psychological distress, and for comprehensive psychosocial support for all patients with advanced cancer throughout the disease trajectory. In turn, our findings also reinforce the need for correct malnutrition screening and nutritional counseling and support in hospitalized cancer patients.

In conclusion, the presence of anxiety and depression symptomatology in oncological inpatients is high. There is an association between malnutrition and presenting anxious and depression symptomatology in hospitalized oncologic patients. The significant levels of depression and anxiety in these patients indicate the need for early supportive psychotherapy or pharmacological interventions. Further studies are needed to better understand the causality of this association.

Acknowledgements The authors would like to thank all individuals who participated in this study, for their willingness to collaborate. We would also like to thank the staff of the inpatient oncology unit for their assistance in the data collection procedures. The authors are grateful for the grants received from SAEDYN, SANCYD, and Abbott Laboratories SA, which allowed the performance of this study.

Author contribution Conceptualization, F.J.S.-T., M.R.-V., and G.O. Data curation, V.C.-B., F.J.S.-T., and I.G.-A. Formal analysis, F.J.S.-T. and G.O. Funding acquisition, G.O. Investigation, V.C.-B., F.J.S.-T., M.B., and I.G.-A. Methodology, V.C.-B., F.J.S.-T., M.R.-V., and M.B. Project administration, V.C.-B., M.R.-V., and G.O. Supervision, G.O. Writing—original draft, F.J.S.-T.

Funding Open access funding provided by Open Access funding provided thanks to the CRUE-CSIC agreement with Springer Nature. This research was funded in part by the 2017 research grants of SAEDYN (Sociedad Andaluza de Endocrinología, Diabetes y Nutrición) and SANCYD (Sociedad Andaluza de Nutrición Clínica y Dietética) and an unrestricted grant from Abbott Laboratories SA (Spain). V.C.-B. is funded by postdoctoral fellowships from the Junta de Andalucía (RH-01412020). Funding for open access charge: Universidad de Málaga/CBUA.

Data availability The data that support the findings of this study are available from the corresponding author upon reasonable request.

Code availability Not applicable.

\section{Declarations}

Ethics approval The study was approved by the Provincial Research Ethics Committee of Málaga (reference number \#01052016). The ethical principles stated in the latest revision of the Declaration of Helsinki and good clinical practice standards were applied.

Consent to participate Informed consent was obtained from all individual participants included in the study.
Consent for publication Not applicable.

Conflict of interest The authors declare no competing interests.

Open Access This article is licensed under a Creative Commons Attribution 4.0 International License, which permits use, sharing, adaptation, distribution and reproduction in any medium or format, as long as you give appropriate credit to the original author(s) and the source, provide a link to the Creative Commons licence, and indicate if changes were made. The images or other third party material in this article are included in the article's Creative Commons licence, unless indicated otherwise in a credit line to the material. If material is not included in the article's Creative Commons licence and your intended use is not permitted by statutory regulation or exceeds the permitted use, you will need to obtain permission directly from the copyright holder. To view a copy of this licence, visit http://creativecommons.org/licenses/by/4.0/.

\section{References}

1. Muscaritoli M, Arends J, Bachmann P, Baracos V, Barthelemy N, Bertz H et al (2021) ESPEN Guideline ESPEN practical guideline: clinical nutrition in cancer. Clin Nutr 40:2898-2913. https:// doi.org/10.1016/j.clnu.2021.02.005

2. August DA, Huhmann MB (2009) A.S.P.E.N. Clinical guidelines: nutrition support therapy during adult anticancer treatment and in hematopoietic cell transplantation. J Parenter Enter Nutr 33:472500. https://doi.org/10.1177/0148607109341804

3. Cederholm T, Barazzoni R, Austin P, Ballmer P, Biolo G, Bischoff SC et al (2017) ESPEN guidelines on definitions and terminology of clinical nutrition. Clin Nutr 36:49-64. https://doi.org/10.1016/j. clnu.2016.09.004

4. Arends J, Bachmann P, Baracos V, Barthelemy N, Bertz H, Bozzetti $F$ et al (2017) ESPEN guidelines on nutrition in cancer patients. Clin Nutr 36:11-48. https://doi.org/10.1016/j.clnu.2016. 07.015

5. Contreras-Bolívar V, Sánchez-Torralvo FJ, Ruiz-Vico M, González-Almendros I, Barrios M, Padín S et al (2019) Glim criteria using hand grip strength adequately predict six-month mortality in cancer inpatients. Nutrients 11 . https://doi.org/10. 3390/nu11092043

6. Walker J, Hansen CH, Martin P, Symeonides S, Ramessur R, Murray G et al (2014) Prevalence, associations, and adequacy of treatment of major depression in patients with cancer: a cross-sectional analysis of routinely collected clinical data. The Lancet Psychiatry 1:343-350. https://doi.org/10.1016/S2215-0366(14)70313-X

7. Linden W, Vodermaier A, MacKenzie R, Greig D (2012) Anxiety and depression after cancer diagnosis: prevalence rates by cancer type, gender, and age. J Affect Disord 1411:343-51. https://doi. org/10.1016/j.jad.2012.03.025

8. Mitchell AJ, Chan M, Bhatti H, Halton M, Grassi L, Johansen $\mathrm{C}$ et al (2011) Prevalence of depression, anxiety, and adjustment disorder in oncological, haematological, and palliative-care settings: a meta-analysis of 94 interview-based studies. Lancet Oncol 12:160-174. https://doi.org/10.1016/S1470-2045(11)70002-X

9. Caruso R, Nanni MG, Riba M, Sabato S, Mitchell AJ, Croce E et al (2017) Depressive spectrum disorders in cancer: prevalence, risk factors and screening for depression: a critical review. Acta Oncol 56:146-55. https://doi.org/10.1080/0284186X.2016.12660 90

10. Calderon C, Carmona-Bayonas A, Beato C, Ghanem I, Hernandez $\mathrm{R}$, Majem M et al (2019) Risk of malnutrition and emotional distress as factors affecting health-related quality of life in patients 
with resected cancer. Clin Transl Oncol 21:687-691. https://doi. org/10.1007/s12094-018-1954-9

11. Světláková L, Sláma O, Světlák M, Pochop L, Šedo J, Alexandrová R et al (2019) Prevalence of anxiety and depression and their impact on the quality of life of cancer patients treated with palliative antineoplasic therapy - results of the PALINT trial. Klin Onkol 32:201-207. https://doi.org/10.14735/amko2019201

12. Pitman A, Suleman S, Hyde N, Hodgkiss A (2018) Depression and anxiety in patients with cancer. BMJ 361. https://doi.org/10. 1136/bmj.k1415

13. Shim EJ, Lee JW, Cho J, Jung HK, Kim NH, Lee JE et al (2020) Association of depression and anxiety disorder with the risk of mortality in breast cancer: a National Health Insurance Service study in Korea. Breast Cancer Res Treat 179:491-498. https://doi. org/10.1007/s10549-019-05479-3

14. Mausbach BT, Decastro G, Schwab RB, Tiamson-Kassab M, Irwin SA (2020) Healthcare use and costs in adult cancer patients with anxiety and depression. Depress Anxiety 37:908-915. https://doi.org/10.1002/da.23059

15. Holland JC, Alici Y (2010) Management of distress in cancer patients. J Support Oncol 8:4-12

16. Ma L, Poulin P, Feldstain A, Chasen MR (2013) The association between malnutrition and psychological distress in patients with advanced head-and-neck cancer. Curr Oncol 20:e554. https://doi. org/10.3747/co.20.1651

17. Zhu C, Wang B, Gao Y, Ma X (2018) Prevalence and relationship of malnutrition and distress in patients with cancer using questionnaires 11 Medical and Health Sciences 1117 Public Health and Health Services. BMC Cancer 18:1272. https://doi.org/10.1186/ s12885-018-5176-x

18. Chabowski M, Polański J, Jankowska-Polańska B, Janczak D, Rosińczuk J (2018) Is nutritional status associated with the level of anxiety, depression and pain in patients with lung cancer? J Thorac Dis 10:2303-2310. https://doi.org/10.21037/jtd.2018.03. 108

19. Cederholm T, Jensen GL, Correia MITD, Gonzalez MC, Fukushima R, Higashiguchi T et al (2019) GLIM criteria for the diagnosis of malnutrition - a consensus report from the global clinical nutrition community. Clin Nutr 38:1-9. https://doi.org/10.1016/j. clnu.2018.08.002

20. Sánchez Torralvo FJ, Porras N, Abuín Fernández J, García Torres F, Tapia MJ, Lima F et al (2018) Normative reference values for hand grip dynamometry in Spain. Association with lean mass. Nutr Hosp 35:98-103

21. Douglas E, Mcmillan DC (2018) Towards a simple objective framework for the investigation and treatment of cancer cachexia: the Glasgow prognostic score. Cancer Treat Rev 40:685-691. https://doi.org/10.1016/j.ctrv.2013.11.007

22. Zigmond AS, Snaith RP (1983) The hospital anxiety and depression scale. Acta Psychiatr Scand 67:361-370. https://doi.org/10. 1111/j.1600-0447.1983.tb09716.x

23. Moorey S, Greer S, Watson M, Gorman C, Rowden L, Tunmore $R$ et al (1991) The factor structure and factor stability of the Hospital Anxiety and Depression Scale in patients with cancer. Br J Psychiatry 158:255-259. https://doi.org/10.1192/bjp.158.2.255

24. Ibbotson T, Maguire P, Selby P, Priestman T, Wallace L (1994) Screening for anxiety and depression in cancer patients: the effects of disease and treatment. Eur J Cancer 30:37-40. https://doi.org/ 10.1016/S0959-8049(05)80015-2

25. Carroll BT, Kathol RG, Noyes R, Wald TG, Clamon GH (1993) Screening for depression and anxiety in cancer patients using the Hospital Anxiety and Depression Scale. Gen Hosp Psychiatry 15:69-74. https://doi.org/10.1016/0163-8343(93)90099-A

26. Bjelland I, Dahl AA, Haug TT, Neckelmann D (2002) The validity of the Hospital Anxiety and Depression Scale: an updated literature review. J Psychosom Res 52:69-77. https://doi.org/10. 1016/S0022-3999(01)00296-3

27. Love AW, Kissane DW, Bloch S, Clarke DM (2002) Diagnostic efficiency of the Hospital Anxiety and Depression Scale in women with early stage breast cancer. Aust N Z J Psychiatry 36:246-250. https://doi.org/10.1046/j.1440-1614.2002.01014.x

28. Mackenzie LJ, Carey ML, Sanson-Fisher RW, D’Este CA (2013) Psychological distress in cancer patients undergoing radiation therapy treatment. Support Care Cancer 21:1043-1051. https:// doi.org/10.1007/s00520-012-1624-3

29. Linden W, Vodermaier AA, McKenzie R, Barroetavena MC, Yi D, Doll R (2009) The Psychosocial Screen for Cancer (PSSCAN): further validation and normative data. Health Qual Life Outcomes 7:16. https://doi.org/10.1186/1477-7525-7-16

30. Recklitis CJ, Blackmon JE, Chang G (2017) Validity of the brief symptom inventory-18 (BSI-18) for identifying depression and anxiety in young adult cancer survivors: comparison with a structured clinical diagnostic interview. Psychol Assess 29:1189-1200. https://doi.org/10.1037/pas0000427

31. Brintzenhofe-Szoc KM, Levin TT, Li Y, Kissane DW, Zabora JR (2009) Mixed anxiety/depression symptoms in a large cancer cohort: prevalence by cancer type. Psychosomatics 50:383-391. https://doi.org/10.1176/appi.psy.50.4.383

32. Wiegand A, Zieger A, Staiger RD, Egli A, Freystätter G, BischoffFerrari HA et al (2019) Association of depression with malnutrition, grip strength and impaired cognitive function among senior trauma patients. J Affect Disord 247:175-182. https://doi.org/10. 1016/j.jad.2019.01.013

33. Gosak M, Gradišar K, Rotovnik Kozjek N, Strojan P (2020) Psychological distress and nutritional status in head and neck cancer patients: a pilot study. Eur Arch Oto-Rhino-Laryngology 277:1211-1217. https://doi.org/10.1007/s00405-020-05798-y

34. Zhang X, Pang L, Sharma SV, Li R, Nyitray AG, Edwards BJ (2019) Prevalence and factors associated with malnutrition in older patients with cancer. J Geriatr Oncol 10:763-769. https:// doi.org/10.1016/j.jgo.2019.01.021

35. Britton B, Clover K, Bateman L, Odelli C, Wenham K, Zeman A et al (2012) Baseline depression predicts malnutrition in head and neck cancer patients undergoing radiotherapy. Support Care Cancer 20:335-342. https://doi.org/10.1007/s00520-011-1087-y

36. Van Liew JR, Brock RL, Christensen AJ, Karnell LH, Pagedar NA, Funk GF (2017) Weight loss after head and neck cancer: a dynamic relationship with depressive symptoms. Head Neck 39:370-379. https://doi.org/10.1002/hed.24601

37 dos Santos CA, Ribeiro AQ, de Rosa COB, de Ribeiro RCL (2015) Depressão, déficit cognitivo e fatores associados à desnutrição em idosos com câncer. Cienc e Saude Coletiva 20:751-60. https://doi. org/10.1590/1413-81232015203.06252014

38. Smoliner C, Norman K, Wagner KH, Hartig W, Lochs H, Pirlich $M$ (2009) Malnutrition and depression in the institutionalised elderly. Br J Nutr 102:1663-1667. https://doi.org/10.1017/S0007 114509990900

39. Britton B, Baker AL, Wolfenden L, Wratten C, Bauer J, Beck AK et al (2019) Eating as treatment (EAT): a stepped-wedge, randomized controlled trial of a health behavior change intervention provided by dietitians to improve nutrition in patients with head and neck cancer undergoing radiation therapy (TROG 12.03). Int J Radiat Oncol Biol Phys 103:353-62. https://doi.org/10.1016/j. ijrobp.2018.09.027

Publisher's note Springer Nature remains neutral with regard to jurisdictional claims in published maps and institutional affiliations. 